\title{
A Quick Overview on Geopolymer Chemistry and General Properties
}

\author{
Lais Alves ${ }^{1,2 *}$, Arissa Nogueira' ${ }^{1}$, João dos Santos ${ }^{1}$ and Silvio de Barros ${ }^{1,2}$ \\ ${ }^{1}$ Federal Center of Technological Education Celso Suckow da Fonseca, Brazil \\ ${ }^{2}$ Institut de Recherche en Génie Civil et Mécanique, France
}

ISSN: 2576-8840

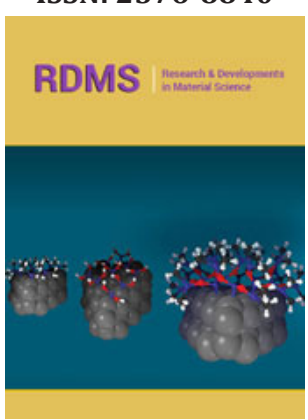

*Corresponding author: Lais Alves, Federal Center of Technological Education Celso Suckow da Fonseca (CEFET/RJ), 229 Av. Maracanã, Rio de Janeiro, Brazil

Submission: 酸 October 11, 2019

Published: 阱 October 24, 2019

Volume 12 - Issue 2

How to cite this article: Lais A, Arissa N, João d S, Silvio de B. A Quick Overview on Geopolymer Chemistry and General Properties. Res Dev Material Sci. 12(2). RDMS.000781.2019.

DOI: 10.31031/RDMS.2019.12.000781

Copyright@ Lais Alves, This article is distributed under the terms of the Creative Commons Attribution 4.0 International License, which permits unrestricted use and redistribution provided that the original author and source are credited.

\begin{abstract}
In civil construction, new materials have emerged as alternatives to reduce the impact of the activity on the environment, one of them is the geopolymer. This material, which can be characterized as a stable and synthesized composite of aluminosilicate materials, has emerged as a potential substitute for Portland cement because it presents similar characteristics of initial strength and good mechanical performance, but without the high emission of carbon dioxide $\left(\mathrm{CO}_{2}\right)$ to obtaining it. This work brings an overview on geopolymer chemical composition and general properties. It is intended to disseminate knowledge as of the state of the art on geopolymer as cement substitute. However, geopolymer cement still needs to be potentially exploited. This requires, among other things, that there be a dissemination of knowledge about the material in the field of civil construction, so that it becomes a known alternative not only in some niches. It is also necessary to develop technological options so that their failures of resistance and mechanical behavior, similar to Portland cement, are overcome.
\end{abstract}

Keywords: Geopolymer; Environment; Sustainable development; Composite structures

Introduction

As Giannopoulou and Panias [1] explained, the main means of production of the geopolymers is through a reaction composed of a solid phase, called precursor, and a liquid phase, knownas activator. The precursor is characterized by reactive aluminosilicate materials, frequently used metakaolin and fly ash. The activator is composed of an alkaline solution, usually sodium hydroxide $(\mathrm{NaOH})$ or potassium hydroxide $(\mathrm{KOH})$. In general, regardless of the aluminosilicate material used, the macroscopic characteristics of the product will be similar. However, there will be variation-often significant-in the microstructure, affecting also the chemical, mechanical and thermal properties. This variation will depend on which material was used and what were its molar ratios [2].

\section{Chemistry of geopolymer}

In the case the precursor used is metakaolin, what will potentially influence the properties of the geopolymer will be the process of obtaining it, that is, how its calcination is done. The procedure begins with the evaluation of the quality of the kaolinite clays in their reserves, and then ploughing of the material. The kaolinite, then, is collected by gravity and is sent to the processing plant, where the product has acquired characteristics that make it employable in the manufacture of the geopolymer. Next is the kaolinite calcination step, obtaining metakaolinite, which consists of a crystalline mineral, with a generally white coloration, good chemical inertia and fine grain size [3]. This transformation can be described by:

$$
\mathrm{Al}_{2} \mathrm{O}_{3} \cdot 2 \mathrm{SiO}_{2} .2 \mathrm{H}_{2} \mathrm{O} \rightarrow \mathrm{Al}_{2} \mathrm{O}_{3} \cdot 2 \mathrm{SiO}_{2}+\mathrm{H}_{2} \mathrm{O}[1]
$$

This process is characterized by a higher energy consumption, since the temperature used normally varies from $600^{\circ}$ to $900^{\circ} \mathrm{C}$. In addition to the metakaolinite, kaolinite calcination results in water, which does not cause environmental damage, unlike $\mathrm{CO}_{2}$ emitted during the calcination process of Portland cement. This is one more factor that makes geopolymer more environmentally friendly, from a sustainable point of view [3]. Regarding the activators, the choice will depend on characteristics such as the viscosity and heat of their dissolution. Among the possible alkaline solutions within these parameters, the most commonly used is the basic solution of sodium hydroxide $(\mathrm{NaOH})$. This choice is related to the low cost of production, easy availability and low viscosity [4]. The chemical matrix of the geopolymers, starting from 
the aluminosilicates, consists of a three-dimensional tetrahedral network formed by silicon and aluminum atoms, intercalated and connected by oxygen atoms at the vertices. Such a structure is called silicoxo-aluminate or, in short, sialato. The sialate is the basic unit, which can be combined in repeating units called polyciliate [5]. The polymerization process is of the polycondensation type, with an intermediate formation of a gel phase, called "geopolymeric binder gel phase". This phase is composed of disorganized alkali aluminosilicates, where there are also some non-reactive precursor particles and a network of pores of the gel, resulting from water incorporated in the alkaline solution [4].

The first step in this process is the dissolution of the solid aluminosilicate in the activator solution, the main characteristic of this phase is the high $\mathrm{pH}$ resulting from the solution of alkali metal cations by the solution, accelerating the process. Condensation will begin after this step, which results in increased concentrations of aluminum and silicate. This $\mathrm{Si} / \mathrm{Al}$ ratio, present in the final structure, will substantially influence the properties of the resulting geopolymer [6]. The process of synthesis of the geopolymer can be summarized as described in equation 2 and in the conceptual model found in Figure 1.

$$
\mathrm{Mn}\left[-\left(\mathrm{Si}-\mathrm{o}_{2}\right) z-\mathrm{Al}-\mathrm{o}\right] n . \mathrm{wH}_{2} \mathrm{O} \text { [2] }
$$

where: M: cation from the alkaline element; $n$ : degree of polymerization;

z: equal to 1, 2 or 3; w: degree of hydration.

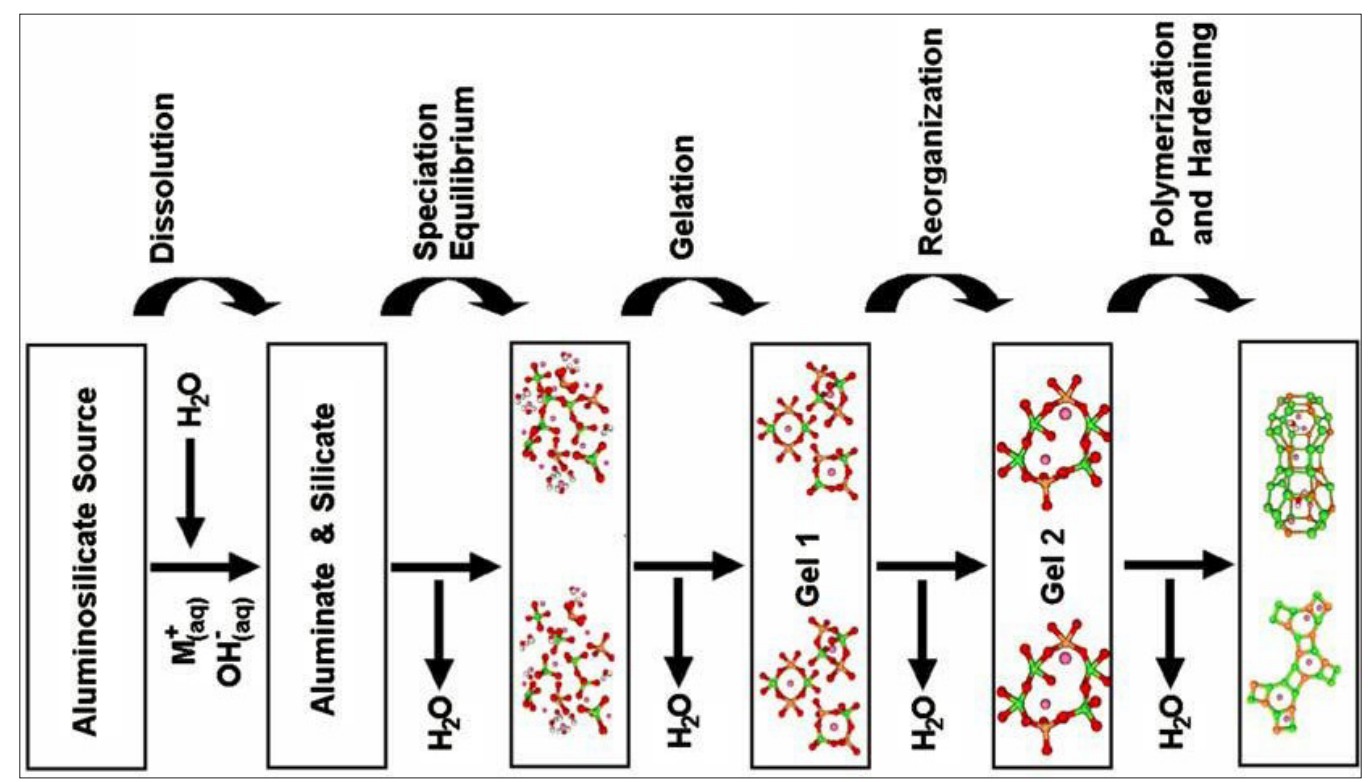

Figure 1: Theoretical schematic model for geopolymers synthesis (Duxson et al. [9])

Thus, according to Meier and Olson [7], the geopolymer cement can be compared chemicallyand structurally with the zeolites, since the zeolites also have a three-dimensional tetrahedral arrangement, consisting of silicates and aluminosilicates interconnected by oxygen atoms. What differentiates the two compounds is, in fact, their atomic structures. This distinction occurs due to different rates of synthesis; the geopolymer cements have a faster synthesis and there is no time to develop a crystalline structure from the formation of the gel. What happens in this case is the formation of an amorphous or semi-crystalline structure, as opposed to the crystalline, cage-like structures of the zeolitic minerals [8].

\section{General properties of geopolymer}

The properties of the geopolymers are directly linked to the raw materials used and the synthesis conditions for their manufacture. That is, the aluminosilicates and activators used actively impact the final product. This is because these parameters are determinant in the microstructural characteristics of the product. These characteristics define the main properties of geopolymers, such as low shrinkage, high compressive strength, low thermal conductivity and durability against acidicattacks. Nevertheless, studies have also found that parameters such as resistance are not affected by the variation of the alkaline solution used or the cure time, being equal to 7 or 28 days. However, the activator is able to directly affect the modulus of elasticity [9]. Bentur and Mindess [10] also showed that, although they are resistant to compression, geopolymer cement, like Portland cement, has low tensile strength and is susceptible to deformation. A solution for increasing the strength as well as the durability and granting of volumetric stability is the use of aggregates in the geopolymer mixture, taking care that the chosen aggregate is not reactive towards the components of the geopolymer so as not to affect the preparation or the cure [11].

The thermal resistance attributed to geopolymers comes from their amorphous and inorganic structure. This capability has been the subject of several studies, such as those of Kong and Sanjayan [12] that concluded that the resistance to high temperatures would influence the $\mathrm{Si} / \mathrm{Al}$ ratio contained in the sample from metakaolin-based geopolymer samples. Other studies were carried out by Davidovits [5], through which a good resistance to heat was observed when the mixture is made from potassium silicate, sodium and metakaolin, reaching thermal stability at temperatures 
above $1200^{\circ} \mathrm{C}$. This characteristic makes the material important in the development of structures with greater solidity in front of the high temperatures and the action of the fire and can even be used in the development of refractory materials [12]. Another important feature that transforms the geopolymer into a useful material in the development of new technologies is the resistance to attack of acidic chemical agents. This durability comes from another important property: the low apparent porosity that results in a low water permeability, imparting mechanical resistance to freeze-thaw cycles. This attribute makes geopolymer cement a product with high chemical durability and a potential resource for encapsulation and management of toxic and radioactive waste [1].

\section{Final considerations}

Concrete is used as main material in civil construction worldwide. The use of geopolymer mortar promotes energy efficiency of constructions reflecting in significant gains in the environmental field [13]. Geopolymers exhibit different properties and characteristics, depending on the raw materials selection and processing conditions. In addition, geopolymers can be synthesized from a different type of low-cost alumina-silicate materials or even industrial wastes, such as fly ash, metakaolin, furnace slag, and rice husk ash. The overview presented the chemical and general properties of geopolymers, that is an innovative material and that little by little is becoming a viable alternative for the total or partial replacement of Portland cement in the manufacture of concrete used in civil construction, today one of the main responsible for environmental degradation, a model of sustainable development.

\section{References}

1. Giannopoulou L, Panias D (2007) Structure, design and applications of geopolymeric materials. Proceedings of the $3^{\text {rd }}$ international conference on deformation processing and structure of materials, Serbia, pp. 5-15.
2. Vickers L, Van R, Arie R (2015) Fire resistant geopolymers: Role of fibres and fillers to enhance thermal properties, Springer, USA.

3. Netto RM (2006) Materiais Pozolânicos. Monografia (Especialização em Construção Civil), Universidade Federal de Minas Gerais, Brazil.

4. Provis JL, Van Deventer JSJ (2009) Geopolymers: structures, processing, properties and industrial applications, Elsevier.

5. Davidovits J (1994) Properties of geopolymer cements. Geopolymer institute. First international conference on alkaline cements and concretes, Ukraine, pp.131-149.

6. Buchwald A, Zellmann H-D, Kaps CH (2011) Condensation of aluminosilicate gels: model system for geopolymer binders. Journal of non-crystalline solids 357(5): 1376-1382.

7. Meier WM, Olson DH (1992) Atlas of zeolites structure types. (3 $3^{\text {rd }}$ edn), Butterworth-Heinemann, London.

8. Davidovits J (1984) Lone star industries a corp of connecticut. Synthetic mineral polymer compound of the silicoaluminates family and preparation process.

9. Duxson P, Lukey GC, Deventer JSJ (2006) Thermal evolution of metakaolin geopolymers: Part 1- Physical evolution. Journal of Non-Crystalline Solids 352(52-54): 5541-5555.

10. Bentur A, Mindess S (2006) Fibre reinforced cementitious composites. $2^{\text {nd }}$ edn, CRC Press, USA.

11. Kriven WM, Siah LF, Schmucker M, Schneider H (2004) High temperature microhardness of single crystal mullite. Journal of the American Ceramic Society 87(5): 970-972.

12. Kong DLY, Sanjayan JG (2010) Effect of elevated temperatures on geopolymer paste, mortar and concrete. Cement and concrete research 40(2): 334-339.

13. Livi CN (2013) Desenvolvimento de pasta de geopolímeros a base de cinza volante e hidróxido de sódio. Brazil. 